\title{
INTERFACES ENTRE GÊNERO E SAÚDE MENTAL ABORDADAS POR ESTUDOS QUALITATIVOS DAS CIÊNCIAS SOCIAIS E HUMANAS: FOCO NAS EXPERIÊNCIAS SUBJETIVAS
}

\section{Tahiana Meneses Alves ${ }^{1}$}

Resumo: $\bigcirc$ presente trabalho consiste em uma revisão de literatura do tipo narrativa que tem por objetivo destacar produções brasileiras de cunho empírico que englobam o gênero enquanto categoria analítica no campo da saúde mental. Possui como recorte estudos qualitativos que focalizam as experiências subjetivas face a própria saúde mental. Os estudos foram identificados através de base de dados como a Scielo e a Biblioteca Digital Brasileira de Teses e Dissertações. A revisão evidencia a necessidade de mais estudos que considerem as perspectivas das pessoas face a própria saúde mental levando em conta uma abordagem de gênero; constata a escassez de estudos sobre a saúde mental masculina; demonstra que condições desiguais de gênero diferenciam as formas de adoecer entre homens e mulheres, bem como produzem impactos distintos para eles e elas em diversas esferas da vida. Aponta para a importância do registro e da análise sobre como as pessoas elaboram diferentes sentidos em torno de suas experiências de saúde mental para além de perspectivas biologicistas.

Palavras-chave: gênero; saúde mental; estudos qualitativos.

Abstract: This study realizes a literature review of the narrative type about Brazilian empirical productions that encompass the gender as analytical category in the field of mental health. It covers qualitative studies about subjective experiences with psychic suffering. The studies were identified through a database as Scielo and Biblioteca Digital Brasileira de Teses e Dissertações. The review evidences the need for more studies that consider the perspectives of people towards their own mental health encompassing a gender approach. Even more, research investigating the masculine condition. It shows that unequal gender conditions differentiate forms of illness between men and women and produce 
distinct impacts for them in various spheres of life. It points to the importance of analyzing and recording how people construct different meanings around their mental health experiences beyond biologicist perspectives.

Keywords: gender; mental health; qualitative studies.

\section{Introdução}

Desde a década de 1970, está em curso no Brasil a chamada Reforma Psiquiátrica, processo que visa a construção de um novo estatuto social para as pessoas com transtornos mentais. Junto ao movimento da Luta Antimanicomial, a Reforma vem produzindo mudanças em diversas esferas (aparatos jurídicopoliticos, qualidade dos serviços prestados, transformações socioculturais) e promovendo a chamada desinstitucionalização.

No interior desse contexto, a Política Nacional de Saúde Mental brasileira (materializada especialmente pela lei 10.216/2001) objetiva humanizar os serviços de saúde mental no Brasil e tem como proposta geral promover uma mudança sociocultural no relacionamento entre sociedade e loucura. Tudo isso pode causar alterações nas vidas das pessoas que dela usufruem. Mas, como atentam Andrade e Maluf (2016), as experiências dos sujeitos nestes serviços estão impregnadas dos lugares relacionais e hierárquicos e também por processos de (des)subjetivação nos quais se geram estratégias micropolíticas de sujeição e resistência. Entre os fatores que rondam estas experiências está o gênero. Este conceito, que passou a ser utilizado entre as décadas de 1970 e 80 , diz respeito à construção social entre os sexos, dá significado a relações de poder (SCOTT, 1990) e se articula a outros sistemas de classificação social e produtores de desigualdade como a raça/etnia, classe social etc.

Como sustenta Maluf (2010), as transformações decorrentes da Reforma são altamente marcadas por questões de gênero, seja nas políticas públicas, nas práticas assistenciais e até mesmo no ativismo político. Também atenta Andrade (2014) que a intersecção do gênero com outras categorias como raça/etnia e classe acaba marcando relações de poder que se reproduzem nos serviços substitutivos como os CAPS tal e qual nos hospitais psiquiátricos que ainda existem. Acontece que nem sempre estes aspectos são observados. 
As interfaces entre gênero e saúde mental ainda são pouco abordadas. Seja em termos de estudos científicos (BEZERRA, 2017; DANTAS, 2016; ZANELLO, 201 e 2017) ou de intervenções (ANDRADE, 2014; MALUF, 2010), tais entrelaçamentos são insuficientemente notados, o que causa impactos improdutivos especialmente às pessoas que têm algum sofrimento psíquico. Ainda é pouco o investimento sobre esta relação para além de questões biomédicas. Menos ainda são levadas em conta as experiências e os significados que o sofrimento psíquico e/ ou o transtorno mental tem para aqueles e aquelas que os vivenciam.

Em contrapartida, o que há em demasia são concepções de gênero estereotipadas presentes em discursos e práticas sobre homens e mulheres quanto à saúde mental. Por exemplo, a de que as mulheres são naturalmente mais propensas (física ou psicologicamente) à enfermidade (BUSFIELD, 1996), o que pode ser visualizado através de afirmações como "depressão é coisa de mulher" (ZANELLO, 2014 e 2017). Outro exemplo da insuficiente abordagem é oferecido por Maluf (2010) e diz respeito a pesquisas acadêmicas, políticas institucionais/governamentais e até movimentos sociais que atuam na área da saúde: quando, por acaso, consideram as diferenças entre homens e mulheres, isto frequentemente ocorre guiado por uma perspectiva que prioriza os corpos (biologicamente falando) em detrimento de outros aspectos (como os socioculturais, por exemplo).

Sob esta lógica, torna-se lugar comum que as mulheres, vitimizadas por sua própria biologia, sejam mais conduzidas à psiquiatrização, à patologização (BONINO, 2000) e à medicalização (MALUF, 2010). Por outro lado, os homens permanecem sendo menos alvo de tratamentos e estudos porque, de certa maneira, continuam invisiveis no campo do "mental" (BONINO, 2000). Estas perspectivas, muitas vezes baseadas em um fundacionalismo biológico, acabam ofuscando a complexidade da questão. Ademais, como atenta Andrade (2014), mesmo movimentos dentro da Reforma Psiquiátrica, embora tenham preceitos antimanicomiais, podem acabar produzindo regimes de subjetivação como o gênero em seus processos de desinstitucionalização.

O transtorno mental não constitui uma realidade acabada e bem delimitada. Não é uma entidade que independe da sociedade e da cultura. $\bigcirc$ modo pelo 
qual é concebido depende da experiência particular de cada indivíduo. Por sua vez, cada experiência depende da posição social que estes indivíduos ocupam, bem como da cultura na qual se inserem. É de suma importância perceber a estrutura global das condições femininas e masculinas através de uma perspectiva de gênero em vez de ver os sintomas como estritamente individuais e encerrados nos seus componentes biológicos ou psicológicos. Assim, priorizamos o gênero enquanto marcador sociocultural que se relaciona com a saúde mental. Partimos da perspectiva de Connell e Pearse (2015, p. 42): "O gênero é a estrutura de relações sociais que se centra sobre a arena reprodutiva e o conjunto de práticas que trazem as distinções reprodutivas sobre os corpos para o seio dos processos sociais".

Algo importante a ser justificado é que embora tenhamos realizado nossa revisão desde uma perspectiva "dual" (no sentido de tratar, por um lado, do "grupo" de homens e, por outro, do "grupo" de mulheres), isto não significa que deixamos de considerar a complexidade do real. Como informam Connell e Pearse (2015), a vida humana não está dividida em apenas duas esferas e nem o caráter humano se divide apenas em dois tipos. Inclusive, isto aparece nos resultados dos estudos selecionados - as diferenças entre as próprias mulheres e as diferenças entre os próprios homens. No entanto, foi necessário recorrer a um binarismo estratégico (SPIVAT apud ZANELLO, 2017) para executar a análise. E a despeito da diversidade de masculinidades e feminilidades existentes, não podemos deixar de considerar o peso que "caminhos privilegiados de subjetivação específicos para homens e mulheres" (ZANELLO, 2017, p. 5) têm sobre a saúde mental.

Dito isto, este trabalho tem como objetivo realizar uma revisão de literatura sobre a produção científica que engloba o gênero enquanto categoria analítica no campo da saúde mental. E, para tal, optamos por fazer o recorte de estudos empíricos que investigam as experiências a partir da perspectivas das próprias pessoas que vivenciam um sofrimento psíquico e/ou são diagnosticadas com algum transtorno mental. A questão que fundamenta tal revisão é: "como homens e/ou mulheres, a partir de uma abordagem de gênero, experienciam o próprio sofrimento psíquico/transtorno mental?".

As informações contidas na revisão podem contribuir para que se compreenda a saúde e o transtorno mental como fenômenos multifacetados, que não 
devem ser explicados apenas ou primordialmente por perspectivas individuais, biologicistas, muitas vezes a-históricas. Vão muito além do que está contido nos manuais oficiais que, por sinal, não são completamente neutros. Conhecer as experiências das pessoas quanto à saúde mental ajuda a desmistificar a suposta vulnerabilidade física e/ou psicológica, ao longo da história, atribuída especialmente às mulheres (BUSFIELD, 1996). Também contribui, em conformidade com as premissas da reforma psiquiátrica, para que se considere mais e mais as experiências singulares das pessoas usuárias dos serviços, suas histórias, seus hábitos, do que precisam etc. e como o gênero ronda tudo isto. As contribuições também podem englobar políticas, gestores, trabalhadores do campo da saúde mental, especialmente quanto à possibilidade de superar intervenções pautadas primordialmente na medicalização dos sintomas.

\section{Metodologia}

Trata-se de uma revisão narrativa sobre produções empíricas brasileiras que relacionam gênero e saúde mental. Os estudos foram identificados através de buscas nos bancos de dados especialmente da BDTD (Biblioteca Digital Brasileira de Teses e Dissertações) e da Scielo (Scientific Electronic Library Online). O objetivo da revisão narrativa é elencar publicações amplas, adequadas para descrever e discutir o "estado da arte" de um determinado assunto, sob ponto de vista teórico ou contextual. Propicia que o leitor adquira e atualize o conhecimento sobre uma temática específica em um curto espaço de tempo (ROTHER, 2007). Vale ressaltar que a revisão narrativa ou tradicional possui uma temática mais aberta, não necessariamente parte de uma questão específica, não exige um protocolo rígido para a confecção, bem como engloba critérios de seleção definidos pelo autor - diferentemente de revisões sistemáticas (CORDEIRO et al., 2007). Assim, a ideia foi realizar um panorama exploratório dos estudos qualitativos que tratassem do tema mais amplo "gênero e saúde mental" a partir das experiências das pessoas quanto à própria saúde.

Desta forma, estabelecemos enquanto critérios de inclusão dos estudos: serem produções sobre a realidade brasileira, publicadas desde a década de 1990 até 2017, que utilizassem metodologias qualitativas e tivessem como alvo de suas análises os relatos, histórias de vida, experiências, narrativas, concepções 
etc dos sujeitos face à própria saúde mental. Convém destacar que nem sempre os estudos aqui mencionados adotaram especificamente a categoria "gênero", mas devido ao fato de terem desenvolvido suas análises em torno das condições sociais de vida de mulheres e homens, achamos pertinentes incluí-los na revisão. Selecionamos artigos, livros, trabalhos de conclusão de curso/especialização, teses e dissertações que tratavam das temáticas gênero, saúde mental, doença mental, transtorno mental, sofrimento psíquico, loucura, nervoso, mulheres, homens, saúde mental masculina, saúde mental feminina.

Os estudos selecionados podem ser enquadrados na área das ciências sociais e humanas ${ }^{2}$. Assim, excluímos as produções voltadas prioritariamente para os componentes individuais (biológicos, psicológicos) da saúde mental de homens e mulheres. Também excluímos aqueles estudos que, embora tratem dos fatores sociais de risco à saúde mental, o façam a partir de uma abordagem epidemiológica e, consequentemente, com uma metodologia diferente (geralmente de caráter quantitativo) que não foca nas perspectivas dos sujeitos.

\section{Gênero e saúde mental: o foco nos sujeitos das experiências}

As ciências sociais e humanas ajudam a compreender o campo da saúde mental a partir de variadas bases teórico-metodológicas. Analisam, por exemplo, como fatores sociais que contribuem para o surgimento de transtornos mentais (MEDEIROS, 2016; RODRIGUES, 2015); identificam quais populações são mais propícias a sofrer com transtorno " $x$ " ou " $y$ " (CAMPOS, 2016). Também problematizam como certos conceitos de saúde e doença mental mudam ao longo do tempo (CAMPOS, 2016; MORAIS, 2014), discutem a fronteira entre ○ "normal" e o "patológico" (NASCIMENTO, 2015), o estigma oriundo da carreira de doente (NASCIMENTO, 2015), a qualidade dos serviços e cuidados oferecidos em saúde mental (MEDEIROS, 2016; MUYLAERT, 2016) e, como veremos a seguir, as experiências de pessoas quanto à sua saúde mental.

Esses diferentes tipos de análise também têm contribuído para que se entenda melhor a relação entre saúde mental e gênero. Conforme Ordorika Sacristán (2009), introduzir uma perspectiva de gênero no campo da saúde mental significa

2 Mesmo alguns que, a princípio, sejam incluídos na grande área das ciências da saúde como, por exemplo, alguns estudos da enfermagem porque, além de se enquadrarem nos critérios de inclusão estabelecidos para esta revisão, apresentavam referenciais teórico-metodológicos fundamentados em textos das ciências sociais e humanas. 
um avanço qualitativo face às abordagens tradicionais caracterizadas pela alta generalização e pela tendência de categorizar todas as pessoas com transtornos mentais como um grupo único e indiferenciado.

Segundo a autora, quanto ao gênero no campo da saúde mental, um desses tipos de análise engloba trabalhos sobre os processos sociais e as concepções de saúde, doença mental e categorias diagnósticas. Busca visibilizar e criticar os traços de gênero que elas contêm. Outro tipo de análise foca na relação entre os processos sociais e as práticas médicas específicas, investigando como a psiquiatria colabora para produzir controle sobre as mulheres. Um terceiro tipo estuda como se relacionam os processos sociais e a etiologia das enfermidades mentais, partindo da situação de iniquidade que marcam a vida das mulheres. Por fim, um quarto tipo se ocupa das experiências dos indivíduos a partir da sua própria condição e tenta entender como gêneroestá presente nas vivênciasde sofrimento (ORDORIKA SACRISTÁN, 2009).

Neste artigo, o recorte da revisão narrativa foi realizado em conformidade com este último tipo: o das experiências subjetivas com o sofrimento psíquico e/ou o transtorno mental. Assim, como afirma Hita (1998), mais que identificar os fatores estressores do meio social, tal qual fazem abordagens epidemiológicas, analisa-se as experiências que se desenvolvem ao longo das trajetórias de vida e refletem a maneira pelas quais os indivíduos se situam e atribuem sentidos a diversas situações.

Segundo Ordorika Sacristán (2009), este tipo de pesquisa surgiu pela década de 1980 com o interesse de conhecer, além dos discursos e práticas médicas, as perspectivas dos pacientes de saúde. Ousou ir além do modelo sociológico parsoniano de paciente, caracterizado como passivo, e passou a focar na capacidade de reflexão sobre o discurso médico e na elaboração de conceitos e ações diferentes das prescritas pelos profissionais. Em tal abordagemos pacientes são considerados sujeitos ativos pois disponibilizam os significados que dão às suas experiências com a saúde e a doença, criam conhecimento a partir dessas experiências e desenvolvem estratégias para lidar com elas. Os seus trabalhos geralmente utilizam técnicas de narrativas e entrevistas em profundidade. Mas também mostram que as experiências subjetivas não se constituem sem a 
influência das condições de vida das pessoas, o que inclui as de gênero.

Este tipo de análise que prioriza as experiências leigas quanto à saúde mental tem se expandido, mas pode se considerar que ainda de maneira incipiente. No âmbito da saúde mental, como informa Andrade (2012), os estudos que avaliam os impactos das práticas e políticas, por exemplo, são voltados majoritariamente para captar os pontos de vista de trabalhadores e gestores do campo em detrimento dos "experientes", isto é, dos usuários de serviços de saúde. Menos ainda são aqueles que investigam as perspectivas dos "experientes" em função do gênero. Dito isto, elencamos abaixo alguns estudos brasileiros que elegeram como objeto empírico pessoas em sofrimento psíquico e/ou com transtorno mental e investigaram suas experiências em saúde mental na interface com as relações de gênero.

Um dos trabalhos é o de Tsu e Tofolo (1990). No artigo, os autores investigaram as concepções etiológicas de pacientes psiquiátricas sobre a própria doença mental. Averiguaram de que maneira o discurso organicista hegemônico na assistência psiquiátrica aparece na fala das pacientes e descobriram que, entre elas, predominam explicações de cunho psicossocial. Entrevistaram 60 mulheres internadas no Hospital Psiquiátrico de Vila Mariana, São Paulo, e constataram que as suas explicações remetem para situações de problemas nos relacionamentos interpessoais (especialmente os familiares). Mesmo quando relatam sintomas orgânicos (dor de cabeça, desmaio, falta de apetite, consumo de álcool etc.) ou "espirituais" (encosto, "trabalho", mediunidade mal desenvolvida) associam aos relacionamentos. Há casos de envolvimento problemático com pais, maridos, filhos que remetem para vivências de violência física, desilusões amorosas, sobrecarga no cuidado com crianças entre outras.

Outro trabalho é o de Garcia (1995). No fim da década de 1980, a autora conversou com 68 mulheres na faixa etária entre os 16 e 67 anos sobre os motivos de suas internações e suas experiências em hospitais psiquiátricos em São Paulo. Identificou várias tensões às quais as mulheres são submetidas ao longo da vida: trabalhos fora do lar, cuidados com a casa, partos perigosos, casamentos problemáticos, situações de violência, engravidar e não ter um marido etc. Algumas mulheres da pesquisa apresentam atitudes "masculinas" como atos agressivos, beber, isolar-se ou, ao menos, contra a "natureza feminina" como 
não querer casar, querer viver sozinha, desafiar pais e maridos. Estas mulheres vivenciam um mundo contraditório, mas, na prática, existe um "único" caminho para seguir: ou ela é "natureza" ou "não é mulher" e, assim, sofrem consequências como a exclusão da esfera "natural", o que corresponde à loucura.

Hita (1998), a partir de uma perspectiva da sociologia da saúde e da antropologia médica, investigou experiências potencialmente fragilizadoras da saúde mental nas trajetórias de vida de 14 mulheres auto-referidas como nervosas em uma comunidade de baixa renda de Salvador, Bahia. As "nervosas" entrevistadas referem episódios marcados por restrições econômicas e carências de ordem afetiva na primeira infância. Também há relatos de estupro, um deles conduzindo a uma gravidez na adolescência. Casos de estupro vivenciados por outros membros da família também são identificados como relacionados com o surgimento da crise nervosa entre as mulheres. Na vida adulta, uma das principais queixas está voltada para a vida a dois com relatos de infidelidade conjugal e violência por parte do companheiro. De maneira geral, os conflitos amorosos aparecem mais entre as mulheres mais jovens. As mulheres mais velhas referem preocupações com filhos, netos e outros parentes relacionadas principalmente com os relacionamentos conjugais daqueles e/ou com seus envolvimentos em atividades ilícitas (como o tráfico de drogas). $O$ tema da sexualidade também surgiu seja para as mulheres que relatam a ausência de relações sexuais ou para aquelas que possuem dificuldades na vida sexual com os companheiros. Apesar desses eventos estressores, algumas mulheres encontram alternativas e/ou soluções para eles através do divórcio, separação, mudança de casa, alívio dos papéis de cuidadora, aquisição de um novo trabalho, constituição de novas relações etc.

Silveira (2000) realizou uma abordagem antropológica do "caso dos nervos" com mulheres na localidade de Campeche, cidade de Florianópolis, sul do Brasil. A sua investigação demonstrou como as dimensões físicas, psicológicas e sociais das experiências não são desagregadas. Partiu da noção de "nervos" enquanto fenômeno polissêmico, uma explicação tanto quanto uma forma de expressão para se referir ao cansaço, fraqueza, irritabilidade, tremores, conflitos conjugais e sociais, cefaleias, iras, ressentimentos, privações afetivas ou materiais entre outros aspectos. A etiologia dos "nervos" está nos fatores sócio- relacionais, mas a experiência da paciente é física. A autora, médica e antropóloga, argumentou 
que, na biomedicina, as consultas médicas despojam esta noção dos seus significados e conteúdos sociais e, em geral, desmerecem o sofrimento do paciente ao olhar para este apenas como um "nervoso". Através de entrevistas com 13 mulheres, de idades e histórias diversas, que têm em comum o rótulo de "nervosas", Silveira concluiu que: nervos é um problema das mulheres; constitui para elas uma linguagem social; e pode representar uma forma dissimulada de exercer violência sobre outros atores nos seus cotidianos.

Oliveira (2000) realizou um estudo sobre o consumo de Diazepam por mulheres usuárias do sistema público de saúde na cidade de Sobral, Ceará. A autora verificou que não há acompanhamento sistemático nem registro da prescrição no prontuário das usuárias, o que significa que o tempo de consumo pode não ser monitorado pelos médicos prescritores. Também percebeu que as mulheres veem no medicamento uma forma de alívio para as suas preocupações cotidianas que, frequentemente, estão relacionadas com a classe social desprivilegiada da qual fazem parte: falta emprego, comida, roupa, moradia adequada, educação. Os relacionamentos dessas mulheres também se enquadram nas preocupações. Há predomínio dos relacionamentos conjugais, que englobam uma relação de dominação e violência contra a mulher. Concluiu que a mulher é o alvo mais fácil do complexo médico-hospitalar, que, por sua vez, oferece uma assistência que privilegia o biológico e baseada numa área curativa, fragmentada e restrita.

Sandri (2001) estudou as relações de gênero e a constituição da saúde mental feminina a partir dos sentidos e significados atribuídos ao sofrimento psíquico por mulheres usuárias e também psicólogas de um serviço de saúde mental de Porto Alegre, Rio Grande do Sul. Os sentidos atribuídos pelas mulheres usuárias estão relacionados com a vida cotidiana, destacando-se as responsabilidades e obrigações face ao cuidado com os filhos e familiares próximos. Também os relacionamentos amorosos e as formas de amar surgiram presentes nos relatos. Ainda, o trabalho foi mencionado nos relatos das usuárias e esteve relacionado com a dupla jornada de trabalho e o desemprego.

Alves (2002) realizou uma pesquisa com 10 mulheres idosas e "nervosas" em um dos bairros mais populosos de classe trabalhadora de Salvador, Bahia. Por meio de entrevistas em profundidade, tentou reconstruir os seus "problemas de 
saúde" e histórias de vida. O "nervoso" é descrito como algo incontrolável, que revela reações exageradas face a um dado contexto. Entre as mulheres idosas, o nervoso aparece associado com a vivência cotidiana no bairro: se a rua é espaço de sociabilidade, também é de fofoca no qual o drama pessoal é tornado público. Como forma de aliviar o nervoso, as nervosas recorrem ao médico, aos exames, aos remédios, aos cultos religiosos e também às redes de parentesco e vizinhança. Algumas fazem uso abusivo de medicamento psiquiátrico. A velhice contribui para aumentar o nervoso porque, tal como este, significa perda de autodeterminação que está ligada ao corpo, à impossibilidade de sustentar uma certa identidade pessoal ou a um projeto de vida de acordo com um modelo ideal de mulher (boa mãe, esposa, responsável pela casa). Isto porque as histórias das idosas refletem traições, violências e abandonos pelos seus companheiros. Entretanto, diante dessas dificuldades, podem forjar para si a identidade de mulheres fortes e corajosas.

Rabelo e Souza (2000) investigaram a experiência do nervoso nas trajetórias de vida de 3 mulheres das classes trabalhadoras em Salvador, Bahia. nervoso aparece a partir de alguns temas. $\bigcirc$ primeiro é o do nervoso enquanto enfraquecimento associado com tentativas fracassadas de ocupar uma posição de mulher e mãe segundo o modelo das classes trabalhadoras. Nenhuma delas vê preenchido o papel de marido, pai e provedor por parte de seus companheiros. Enfrentam traições, violências, abandonos. $O$ nervoso também aparece enquanto enfraquecimento do corpo: as mulheres passam por uma perda de sua vitalidade que não ocorre apenas devido ao processo de envelhecimento natural, mas, sobretudo, ao desenrolar de eventos sofridos que deixam marcas no corpo. O enfraquecimento também surge como perda autodeterminação e o nervoso atinge profundamente a sustentação da imagem de si que ora é de uma mulher forte e ousada ora é de uma mulher consumida pela fraqueza.

Couto-Oliveira (2007) realizou um estudo exploratório sobre a interação entre gênero, pobreza, saúde mental e resiliência. A partir de estudos de casos múltiplos com 5 mulheres residentes em uma das comunidades mais pobres do Distrito Federal, identificou dimensões marcantes das experiências de vida dessas mulheres, fatores de risco e proteção para o adoecimento mental e estratégias de enfrentamento indicadoras de resiliência. Segundo os achados da autora, 
- cotidiano das entrevistadas é marcado por dificuldades que impactam várias áreas de suas vidas, sendo que a pobreza, a sobrecarga de trabalho e a violência foram identificadas como os fatores de risco para a saúde física e mental. Os fatores de proteção englobam as redes de apoio na família e no meio social, a espiritualidade e a atitude positiva diante da vida. Por fim, as estratégias de enfrentamento se desdobram a partir dos fatores de proteção que buscam para restabelecer um desenvolvimento saudável.

Saraiva (2008) levou a cabo um estudo sobre as percepções e o modo de lidar com o sofrimento mental por mulheres. Fazendo uso de uma pesquisa qualitativa exploratória, entrevistou 13 mulheres atendidas em serviços de saúde mental ou saúde da mulher (gineco-obstétrico) na cidade de Fortaleza, Ceará. A autora identificou fatores favoráveis ao adoecimento mental feminino: multiplicidade de papéis, separações e perdas; excessos de responsabilidades; gravidez, alterações do ciclo vital; relacionamentos violentos; maus tratos; dependência; isolamento social; maior fragilidade; condições reprodutivas; relações de gênero; maiores preocupações com a família. Entre os efeitos do adoecimento feminino estão: alteração da dinâmica familiar; maior exposição à violência; ausência de vaidade e libido; drogas, gravidez. Concluiu que, frequentemente, este ser feminino, a princípio, não é consciente de ser vítima de um sistema tão bem estruturado de relações desiguais e injustas. Mas, com estímulo, passa a descrever as desigualdades que percebe entre a sua condição e a dos homens. Concluiu ainda que não existe intercambialidade entre os serviços escolhidos como campo de pesquisa no sentido de discutirem as situações das mulheres usuárias.

A pesquisa de doutorado de Silva (2008) abordou a saúde mental a partir de uma perspectiva de gênero focalizando a situação de moradoras de um Serviço Residencial Terapêutico (SRT), na cidade de São José, Santa Catarina, sul do Brasil. $O$ objetivo foi analisar as intersecções entre gênero, sofrimento psíquico, cidadania e subjetividade conforme os pontos de vista das mulheres. A partir de uma pesquisa qualitativa com abordagem etnográfica com 6 residentes do SRT, a autora concluiu que: o SRT funciona tanto como um novo espaço social para as mulheres quanto um dispositivo de controle e poder; que o serviço representa um progresso face à situação anterior das residentes (antes, 
hospitalizadas), mas, em contrapeso, quanto ao gênero, a sua dinâmica propicia a reprodução de papéis femininos tradicionais; por fim, que as desigualdades de gênero estão e estiveram presentes nas trajetórias das entrevistadas, bem como na organização dos SRT femininos e masculinos.

Na coletânea sobre gênero, saúde e aflição, organizada por Maluf e Tornquist (2010), foram registradas algumas investigações de abordagem antropológica em torno das chamadas "experiências sociais" de mulheres com o sofrimento mental. O artigo de Tornquist, Andrade e Monteiro (2010) referiu uma pesquisa de campo em um bairro de camadas populares na cidade de Florianópolis, sul do Brasil, que buscou compreender a dimensão do tratamento e como os próprios sujeitos dão significado a essa experiência em suas vidas cotidianas. A partir de narrativas de mulheres em situação de itinerário terapêutico, as autoras descobriram que tais relatos referem não somente as histórias de vida pessoais, mas também os contextos onde as mesmas são experienciadas. Nos significados em torno do adoecimento, aparecem temas relacionados com a experiência com os médicos, remédios, internações psiquiátricas e religião enquanto opção de alivio e cura, a experiência com a violência no bairro de morada, problemas envolvendo casa, trabalho e gênero - que demonstram os dilemas entre as esferas públicas e privadas. As narrativas situam as vivências com a aflição mais nas experiências individuais e sociais que em explicações de cunho essencialista (relacionadas com o ciclo biológico).

Outro trabalho, desenvolvido por Argenta (2010), destacou a situação de mulheres que participam de uma associação ligada à Pastoral da Saúde em um bairro popular de Florianópolis. A autora verificou que, apesar de todas as entrevistadas aceitarem como legítimos os diagnósticos médicos de depressão que Ihes foram atribuídos, associam estes com outras explicações de cariz religioso, espiritual e social-relacional. Percebeu a importância da rede de sociabilidade na vida destas mulheres e a sua ruptura com um modelo ainda hegemônico de restrição das atividades femininas à esfera doméstica. Neste sentido, a associação comunitária frequentada por estas mulheres funciona como uma espécie de lugar terapêutico onde as próprias mulheres com depressão cuidam de outras pessoas.

O estudo desenvolvido por Brown (2010) retratou a condição de mulheres de terceira idade que são cuidadoras de outras pessoas da família (geralmente a mãe 
ou o marido) em uma comunidade praieira de Florianópolis. A partir da interface entre envelhecimento e aflição, a autora refletiu como o cuidado é tido como uma prática eminentemente feminina - ideia reforçada pela "fofoca" intensa na comunidade. A fofoca envolve tópicos sobre saúde e doença: comentase quem está doente nas suas familias e na comunidade. Aquele (ou "aquela mulher") que tem um ente enfermo tem a obrigação de cuidar do mesmo perante a comunidade. Este cuidado, entretanto, gera uma série de desgastes para as cuidadoras. Os relatos apontam para ansiedade, cansaço, esgotamento, preocupação, estresse, insônia, nervos, depressão.

artigo de Diehl, Manzini e Becker (2010) problematizou o consumo e percepções de/sobre antidepressivos entre usuários de um centro de atenção básica à saúde em Florianópolis. As autoras quantificaram a dispensação de antidepressivos, em especial de fluoxetina, e constataram o já assinalado pela literatura - a maior incidência de mulheres como destinatárias das receitas de medicamentos. As autoras realizaram entrevistas com 3 mulheres usuárias de medicamentos. Perceberam a centralidade que a fluoxetina ocupa na vida das mulheres, bem como a medicalização disseminada não apenas por parte de psiquiatras, mas também por clínicos gerais. Concluíram que o processo saúdedoença não é algo biológico e universal, mas que as experiências individuais sobre o mesmo interferem nos padrões de consumo e nas percepções dos medicamentos por parte dos usuários.

Henriques (2013) refletiu sobre o exercício da maternidade em mulheres com o transtorno mental. Realizou entrevistas semi-estruturadas com perguntas abertas com mulheres-mães usuárias de uma Unidade Docente Assistencial de Psiquiatria no Rio de Janeiro. A autora identificou que a primeira dificuldade dessas mães quanto ao exercício da maternagem, seja no âmbito institucional ou familiar, é a diminuição ou extraviação de seus direitos pelo simples fato de serem diagnosticadas com um transtorno mental. Muitas buscam auxilio médico, psicológico e social especialmente com o desejo de resgatar o vínculo materno. Muitas, mesmo em caso de delírio elou distanciadas há tempos de seus filhos, buscam o direito de exercerem a maternidade, o reconhecimento dos filhos e o amor filial. Concluiu que as necessidades da criança são colocadas à frente das necessidades da mãe devido ao estigma socialmente à loucura que 
a caracteriza como periculosidade. Impede-se, desta forma, o exercício de novas formas de ser mãe na sociedade.

Dantas (2016) investigou sobre a vivência da depressão entre mulheres, bem como o gênero participa na sua formação. A partir de entrevistas semi-estruturadas com 9 mulheres com diagnóstico de depressão em um serviço de saúde público e outro serviço particular de uma capital brasileira, construiu 4 categorias: vivências do círculo feminino, vivências do círculo extra-íntimo, vivências de perspectivas de futuro e vivências de depressão. Predominaram vivências desfavoráveis relativas a um dispositivo materno e um dispositivo amoroso. Por outro lado, foi pouca a referência por parte das mulheres entrevistadas ao seu círculo extraintimo, o que aponta para a limitação de suas vidas ao espaço privado.

Outros trabalhos mostram a associação entre gênero, doença mental e experiência subjetiva a partir dos relatos não apenas de mulheres, mas também de homens. Alves (2008) analisou as perspectivas de homens diagnosticados com o transtorno mental a respeito dos "desencadeantes" do sofrimento, bem como dos impactos dessa vivência em várias esferas da vida. Por meio de entrevistas semiestruturadas e oficinas de grupos com homens internados (a grande maioria era parda e, depois, negra) em um hospital psiquiátrico na cidade de Teresina, Piauí, as categorias "desencadeantes" do sofrimento psíquico apontaram para vivências de violência entre homens (seja como vítimas de agressões físicas no espaço da rua e acidentes automobilisticos). Entre os homens entrevistados, havia aqueles que tinham passado por prisões por terem cometidos crimes como homicídio e estupro. No caso do estupro, dois justificaram o ato: um estuprou a filha de um "bandido" para castigá-lo; o outro disse que estava "chapado" e, além disso, a menina tinha "dado mole". Também apontam para o luto por conta da perda de entes queridos, decepção com a infidelidade conjugal da companheira. $\bigcirc$ uso múltiplo de drogas também é tido como desencadeante do transtorno mental e está associado com um modelo de masculinidade hegemônica que privilegia esta prática como tipicamente masculina e vivenciada em espaços de sociabilidade. Outros homens atribuem o sofrimento ao fato de serem vistos por eles mesmos e/ou por outros como doentes por desviarem de um padrão heteronormativo de sexualidade. Ainda, outros homens relatam problemas com vizinhos, estresse no âmbito do trabalho e mudanças desagradáveis na vida (de bairro, por exemplo). 
Os impactos nas identidades masculinas sinalizam para as esferas da família (perda da autoridade de pai e de provedor, dificuldade de constituir uma família para os solteiros), das amizades (restrição da sociabilidade masculina) e do trabalho (ficar sem trabalhar devido ao transtorno mental afeta não apenas a possibilidade de se sustentar financeiramente, mas atinge a sua honra).

Tinoco (2009) analisou a construção de masculinidades de homens usuários de um serviço de saúde mental no município de Alvorada, Rio Grande do Sul. Através de entrevistas com 5 homens informantes, a autora concluiu que o diagnóstico do transtorno mental interfere na construção de suas masculinidades nos seguintes aspectos: trabalho, conjugalidades e laços familiares, confrarias masculinas (organização/agrupamento de homens que reforçam o pertencimento ao "mundo masculino") e projetos de vida. $O$ trabalho aparece como fator de adoecimento, mas também como algo que não pode ser realizado quando se está doente. Com o adoecimento, há uma "masculinização das mulheres" e "feminilização dos homens" devido à sua condição de alijamento do trabalho e impotência. Quanto às confrarias, os relatos são sobre distanciamento dos antigos grupos de sociabilidade e pertencimento. Quanto aos projetos de vida, o adoecimento provoca uma certa perda de autonomia e até mesmo a desistência ou impossibilidade de desejar, sonhar e fazer planos.

Moura (2011) realizou uma pesquisa sobre homens jovens e a internação psiquiátrica a partir das relações de cuidado pela família. Foram feitos 3 estudos de casos localizados em um hospital psiquiátrico do município de Ribeirão Preto. Foram realizadas entrevistadas com homens que haviam sido internados e com seus familiares. A autora concluiu que os homens vivenciam o sofrimento mental na sua relação com o trabalho e a virilidade, a provisão financeira e o cuidado para com a família. $\bigcirc$ uso de drogas também foi mencionado como possivel disparador para a doença. Ficar internado interfere nos projetos de vida especialmente quanto ao estudo, à profissão e à constituição da própria família. Também interfere nos projetos de vida de seus cuidadores (a maioria mulheres) principalmente quanto à vida social e ao trabalho.

Bezerra (2017), em uma pesquisa quantiqualitativa, analisou os aspectos de vulnerabilidades aos transtornos mentais comuns em homens do estado da 
Paraíba, nordeste do Brasil, comparando os contextos urbano e rural. Na parte qualitativa do estudo, entrevistou 7 homens do contexto rural e 15 do contexto urbano. Para ambos os grupos, o sofrimento psíquico pode ser produto dos problemas familiares e do cuidado para com a família e tem a ver não apenas com o homem enquanto principal provedor da família, mas também enquanto figura ativa no cuidado com os membros familiares (este último aspecto mais presente no contexto urbano). Também são mencionados enquanto causa de adoecimento: crise econômica/dificuldades financeiras, a violência urbana (meios urbanos), a perda da vitalidade física (meios rurais), problemas conjugais, sobrecarga no trabalho (pressões para atingir metas no ambiente de trabalho, medo da demissão para urbanos; trabalho sazonal, trabalho braçal, elevada carga de trabalho agrícola, uso inadequado de agrotóxicos para rurais).

Ainda, outros estudos têm homens e mulheres enquanto objeto empírico. Zanello e Bukowitz (2011) investigaram como os valores e estereótipos de gênero presentes na nossa cultura surgem na "quebra psíquica", isto é, nas experiências de "loucos" e loucas". A análise quanti-qualitativa das falas de pacientes psiquiatrizados em um hospital psiquiátrico de Brasilia revelou a prevalência de queixas relacionais sobre a familia e a vida amorosa para as mulheres e, para os homens, aspectos relacionados com a valorização da virilidade como, por exemplo, a sexualidade ativa, o dinheiro e o trabalho. Zanello, Fiuza e Costa (2015) investigaram o modo como se dava a participação de valores e estereótipos de gênero nas falas de 15 usuários e usuárias de um Centro de Atenção Psicossocial em Brasilia. As entrevistas com os participantes mostraram que, entre os homens, o sofrimento está em torno do fato de não poder trabalhar e sustentar a família e, também, de não poder manter uma sexualidade masculina hegemônica de "comedor". Para as mulheres, o sofrimento está em torno de não conseguir maternar e realizar afazeres domésticos. Zanello, Silva e Henderson (2015) investigaram como a velhice é vivenciada de forma gendrada por 9 homens e 9 mulheres em uma instituição geriátrica particular de Brasilia. Estabeleceram essa vivência na sua relação com a saúde mental. Com base em entrevistas realizadas com idosos e idosas, apontaram que: nas narrativas, as idosas focam nas suas relações amorosas fiéis e monogâmicas, que a sua sexualidade tem como prérequisito o amor e que a família pode ser o objeto de maior ressentimento 
para elas por conta do abandono promovido devido à sua institucionalização; para os homens, o trabalho aparece como peça central no funcionamento identitário, mas colocado em xeque pela velhice. $O$ corpo também é percebido de maneira diferente por mulheres e homens idosos: ambos associam o corpo com perdas e regenerações na velhice, mas, para as mulheres, a imagem e o cuidado corporal surgem relacionados com ideais estéticos de beleza e, para os homens, o corpo é alvo de cuidados básicos.

Santos (2008) analisou a experiência do sofrimento psíquico a partir de relatos de homens e mulheres usuários de um serviço público de Araraquara, São Paulo. As entrevistas realizadas com os participantes apontam para diferentes experiências que diferem não apenas em termos de gênero, mas também indica o efeito da geração e escolaridade. No geral, as mulheres divorciadas e com baixa escolaridade relacionam o sofrimento com o casamento, a maternidade e a violência doméstica. Mulheres solteiras jovens e mais velhas enunciam acontecimentos voltados para a vida amorosa e sexual e vida profissional. Para os homens solteiros jovens e mais velhos, o adoecimento significa uma brusca ruptura em suas trajetórias de vida que se traduz pela sua exclusão do espaço público. Ser homem e estar doente resulta em fracasso social, pouco tolerado pela família e pela sociedade.

\section{Considerações finais}

Dos estudos que encontramos, grande parte elegeu as mulheres enquanto sujeitos da pesquisa. São estudos pertencentes a diversas áreas como a sociologia, a antropologia, a psicologia, a enfermagem, a história entre outras. Nem todos abordam diretamente o conceito de gênero, mas todos, ao focalizarem nas experiências específicas de mulheres elou homens, revelam o quanto a saúde mental, além de ser um fenômeno polissêmico, é experienciada de maneira distinta em função do gênero.

Os resultados dos estudos evidenciam que as condições sociais de vida, bem como os caminhos de subjetivação privilegiados para homens e mulheres são diferentes e, no geral, mais desfavoráveis para elas. Isto porque os homens ainda exercem uma dominação individual e coletiva sobre as mulheres nas esferas privada e pública. Todavia, o peso dos padrões mais vastos e 
persistentes de uma ordem de gênero pode deixar ambos vulneráveis quanto à qualidade da saúde. Os estudos apontam ainda para o peso da intersecção do gênero com outros marcadores sociais que produzem desigualdades como a raça/etnia, a classe social, a orientação sexual etc.

Todos têm em comum o fato de se distanciarem de uma abordagem voltada essencialmente para questões biológicas ao incorporarem os relatos das pessoas em situação de sofrimento psíquico. Suas análises focam nos processos a partir de quem os vivencia. Também se diferenciam teórica e metodologicamente de aportes como o da "produção social da doença mental", os quais utilizam abordagens epidemiológicas que identificam os fatores sociais estressores da saúde mental, mas não englobam os sentidos e os significados que os indivíduos dão e a forma como reagem às condições objetivas.

Esta revisão narrativa possui alguns limites: por não ser do tipo sistemática, isto é, não ter contado com métodos mais sistemáticos para identificar, analisar e avaliar os estudos, possivelmente deixou de fora estudos que poderiam aqui ser enquadrados.

Por outro lado, ao apresentar uma perspectiva ampla do tema em questão, a revisão narrativa pôde trazer algumas contribuições. Primeiramente, sinaliza para a importância de uma compreensão integral dos sujeitos quanto à saúde. Abordagens biológicas, psicológicas, sociológicas/antropológicas etc. da saúde mental precisam dialogar mais entre si.

Revela a necessidade de se produzir mais estudos sobre a saúde mental masculina. Também sobre outras classes sociais na sua intersecção com o gênero: a grande maioria dos estudos aqui selecionados aborda as experiências de sujeitos de classes menos favorecidas e isto pode ter relação com os serviços nos quais foram recrutados os participantes: serviços públicos de saúde/ saúde mental que, mesmo voltados para toda a população, acabam atendendo majoritariamente os segmentos menos favorecidos.

A revisão sugere ainda a confecção de mais estudos com experientes das regiões norte e nordeste, haja vista que grande parte do que foi encontrado e utilizado nesta revisão teve como pano de fundo municípios das regiões sudeste, sul, centro oeste - o gênero também se entrecruza com diferenças regionais 
que podem diversificar as experiências com a saúde/doença. Acrescentamos que outros marcadores de diferenças/desigualdades (inclusive nas experiências quanto à saúde mental) também merecem atenção como a raça/etnia e identidades de gênero e sexualidades contra-hegemônicas.

Os estudos sobre as experiências subjetivas mostram que é possivel rever políticas e intervenções profissionais no dia-a-dia dos serviços quando estes passam a incorporar os aspectos sociais das vidas dos sujeitos que acolhem como o gênero. Temos muito a aprender com os/as experientes. Além disso, tais estudos estão afinados com os princípios da reforma psiquiátrica brasileira, que, na sua dimensão epistemológica, tem fundamento no que a tradição basagliana supõe: pôr a doença entre parênteses e captar o sujeito e suas experiências.

\section{Referências}

ALVES, P. C. Nervoso e experiência de fragilização: narrativas de mulheres idosas. In: MINAYO, M.C.S; COIMBRA JÚNIOR, C.E.A. (orgs.) Antropologia, saúde e envelhecimento [online]. Rio de Janeiro: FIOCRUZ, 2002.

ALVES, T. M. "Boto é pra ferver!": a identidade social de homens com transtorno mental. Trabalho de Conclusão de Curso (Graduação em Serviço Social) - Universidade Federal do Piauí, Teresina, 2008.

ANDRADE, A. P. M. Sujeitos $\mathbf{e}(\mathrm{m})$ movimento: uma análise crítica da reforma psiquiátrica brasileira na perspectiva dos experientes. Tese (Doutorado em Ciências Humanas) - Universidade Federal de Santa Catarina, Florianópolis, 2012

(Entre)laçamentos possíveis entre gênero e saúde mental. In: ZANELLO, V.; ANDRADE, A.P.M. Saúde mental e gênero: diálogos, práticas e interdisciplinaridade. Curitiba: Appris, 2014

ANDRADE, A. P.; MALUF, S. W. Sujeitos e(m) experiências: estratégias micropolíticas no contexto da reforma psiquiátrica no Brasil. Revista de Saúde Coletiva, v. 26, n. 1, 2016.

ARGENTA, M. Itinerários terapêuticos e modelos de sofrimento entre voluntárias da Pastoral da Saúde do Bairro Saco Grande II - Florianópolis/ SC. In: MALUF, S. W.; TORNQUIST, C. S. Gênero, saúde e aflição: abordagens antropológicas. Florianópolis: Letras Contemporâneas, 2010 BEZERRA, E. Saúde mental masculina: prevalência e vulnerabilidades aos transtornos mentais comuns no contexto rural e urbano. Tese (Doutoramento em Psicologia Social) - Universidade Federal da Paraíba, João Pessoa, 2017. 
BONINO, L. Varones, género y salud mental - desconstruyendola "normalidade" masculina", In: SEGARRA, M.; CARABÍ, A. (eds.). Nuevas masculinidades. Barcelona: Icaria, 2000.

BROWN, D. A obrigação de cuidar: mulheres idosas em uma comunidade de Florianóolis. In: MALUF, S. W.; TORNQUIST, C. S. Gênero, saúde e aflição: abordagens antropológicas. Florianópolis: Letras Contemporâneas, 2010.

BUSFIELD, J. Men, women and madness: understanding gender and mental disorder. New York: New York University Press.

CONNELL, R; PEARSE, R. Gênero: uma perspectiva global. Compreendendo o gênero - da esfera pessoal à política - no mundo contemporâneo. São Paulo: Versos, 2015.

CAMPOS, I. O. Saúde mental e gênero em um CAPS II de Brasília: condições sociais, sintomas, diagnósticos e sofrimentos psíquicos. Tese (Doutorado em Psicologia Clínica e Cultura) - Universidade de Brasilia, Brasilia, 2016.

CORDEIRO, A.; OLIVEIRA, G.; RENTERÍA, J.; GUIMARÃES, C. A. Revisão sistemática: uma revisão narrativa. Comunicação científica, v. 34, n. 6, 2007.

COUTO-OLIVEIRA, V. C. Vida de mulher: gênero, pobreza, saúde mental e resiliência. Dissertação (Mestrado em Psicologia Clínica e Cultura) Universidade de Brasilia, Brasilia, 2007.

DANTAS, G. Depressão e gênero: análise da produção bibliográfica brasileira e das vivências de mulheres do Distrito Federal. Dissertação (Mestrado em Psicologia Clínica e Cultura) - Universidade de Brasilia, Brasilia, 2016.

DIEHL, E.; MANZINI, F.; BECKER, M. "A minha melhor amiga se chama fluoxetina": consumo e percepções de antidepressivos entre usuários de um centro de atenção básica à saúde. In: MALUF, S. W.; TORNQUIST, C. S. Gênero, saúde e aflição: abordagens antropológicas. Florianópolis: Letras Contemporâneas, 2010

GARCIA, C. C. Ovelhas na névoa: um estudo sobre as mulheres e a loucura. Rio de Janeiro: Rosa dos Tempos, 1995.

HENRIQUES, C. S. Mulheres com transtorno mental: reflexões sobre o exercício da maternidade. Seminário Internacional Enlaçando Sexualidades. Universidade do Estado da Bahia - Campus I, Salvador, 2013

HITA, M.G. Identidade feminina e nervoso: crises e trajetórias. In: ALVES, P.C.; RABELO, M. C. (orgs.) Antropologia da saúde: traçando identidades e explorando fronteiras [online]. Rio de Janeiro: FIOCRUZ; Rio de Janeiro: Relume Dumará, 1998

MALUF, S. W. Gênero, saúde e aflição: políticas públicas, ativismo e experiências sociais. In: MALUF, S. W.; TORNQUIST, C. S. Gênero, saúde e aflição: abordagens antropológicas. Florianópolis: Letras Contemporâneas, 2010. 
MEDEIROS, M. P. A (in)visibilidade da violência contra as mulheres na saúde mental. Dissertação (Mestrado em Psicologia Clínica e Cultura) Universidade de Brasilia, Brasilia, 2016.

MORAIS, C. A. Concepções de saúde e doença mental: adaptação transcultural do instrumento de Acesso aos Cuidados em Saúde Mental. Tese (Doutorado em Psicologia Clínica e Cultura) - Universidade de Brasilia, Brasilia, 2014.

MOURA, D. Homens jovens e a internação psiquiátrica: relações de cuidado e família. Dissertação (Mestrado em Psicologia) - Universidade de São Paulo, Ribeirão Preto, 2011.

MUYLAERT, C. Gênero e cuidado no campo da saúde mental infantojuvenil. Tese (Doutorado em Ciências) - Universidade de São Paulo, São Paulo, 2016.

NASCIMENTO, A. B. Estigma, sociabilidade e práticas terapêuticas: a terapia comunitára como âncora e alivio do transtorno mental. Dissertação (Mestrado em Sociologia) - Universidade Federal do Pernambuco, Recife, 2015.

OLIVEIRA, E. N. Saúde mental e mulheres: sobrevivência, sofrimento e dependência química lícita. Sobral: Edições UVA, 2000

ORDORIKA SACRISTÁN, T. Aportaciones sociológicas al estudio de la salud mental de las mujeres. Revista Mexicana de Sociologia, v.71, n. 4, 2009.

RABELO, M. C.; SOUZA, I. M. Vida vivida, vivida contada: uma reflexão sobre a experiência do nervoso na trajetória de mulheres de classe trabalhadora em Salvador. XXIV Encontro Anual da ANPOCS, GT-11, "Pessoa, Corpo e Doença", Sessão 1, 2000.

RODRIGUES, M. G. Fatores de risco e proteção para a saúde mental de professores de escolas públicas em Fortaleza (CE) e Porto (PT). Tese (Doutorado em Psicologia Clínica e Cultura) - Universidade de Brasilia, Brasilia, 2015.

ROTHER, E. T. Revisão sistemática x revisão narrativa. Revista Acta Paulista de Enfermagem, v. 20, n. 2, 2007.

SANDRI, G. Gênero e saúde mental: uma análise dos sentidos conferidos ao sofrimento psíquico por usuárias e psicólogas de um serviço de saúde. Dissertação (Mestrado em Psicologia) - Universidade Federal de Santa Catarina, Florianópolis, 2001.

SANTOS, A.M.C.C. Gênero e saúde mental: a vivência de identidades femininas e masculinas e o sofrimento psíquico na sociedade brasileira contemporânea. Algumas reflexões a partir de relatos dos pacientes diagnosticados como portadores de transtornos mentais severos do CAPS - Araraquara - SP. Dissertação (Mestrado em Sociologia) - Universidade de São Paulo, São Paulo, 2008.

SARAIVA, K. V. O. Gênero e saúde mental na atenção primária: a mulher 
como foco de investigação. Tese (Doutorado em Enfermagem) - Universidade Federal do Ceará, Fortaleza, 2008

SCOTT, J. Gênero: uma categoria útil para análise histórica. Educação e Realidade, Porto Alegre, 15 [2], pp. 5-22, 1990.

SILVA, M. A. R. Gênero nos serviços residenciais terapêuticos: "fragmentos de vidas contidas. Tese (Doutorado em Ciências Humanas) - Universidade Federal de Santa Catarina, Florianópolis, 2008.

SILVEIRA, M. L. O nervo cala, o nervo fala: a linguagem da doença. Rio de Janeiro: FIOCRUZ, 2000.

TINOCO, S. M. Articulando gênero e saúde mental: implicações da saúde mental na construção de masculinidades de homens usuários do CAPS II de Alvorada/RS. Trabalho de conclusão de especialização (Especialização em Educação, Sexualidade e Relações de Gênero) - Universidade Federal do Rio Grande do Sul, Porto Alegre, 2009.

TORNQUIST, C. S.; ANDRADE, A. P. M.; MONTEIRO, M. Velhas histórias, novas esperanças. In: MALUF, S. W.; TORNQUIST, C. S. Gênero, saúde e aflição: abordagens antropológicas. Florianópolis: Letras Contemporâneas, 2010

TSU, T. TOFOLO, V. Concepções etiológicas de pacientes psiquiátricas sobre doença mental. Revista Psicologia, v. 1, n. 2, 1990.

ZANELLO, $\mathrm{V}$. A saúde mental sob o viés do gênero: uma releitura gendrada da epidemiologia, da semiologia e da interpretação diagnóstica", In: ZANELLO, V.; ANDRADE, A. P. Saúde mental e gênero: diálogos, práticas e interdisciplinaridade. Curitiba: Appris, 2014.

Saúde mental e gênero. In: $13^{\circ}$ mundos de mulheres $\&$ Fazendo gênero 11: transformações, conexões e deslocamentos, 2017. Florianópolis, Santa Catarina, Brasil, 2017.

ZANELLO, V.; BUKOWITZ, B. Loucura e cultura: uma escuta das relações de gênero nas falas de pacientes psiquiatrizados. Revista Labrys Estudos Feministas, v.20-21, 2011.

ZANELLO, V.; FIUZA, G.; COSTA, H. Saúde mental e gênero: facetas gendradas do sofrimento psíquico. Fractal, Revista Psicologia, v. 27, n. 3, 2015.

ZANELLO, V.; SILVA, L.; HENDERSON, G. Saúde mental, gênero e velhice na instituição geriátrica. Revista Psicologia: teoria e pesquisa, v. 31, n. 4, 2015.

Recebido em maio de 2018.

Aceito para publicação em maio de 2018. 